THE JOURNAL OF

PHILOSOPHICAL ECONOMICS

Volume V Issue 2 Spring 2012

ISSN 1843-2298

Copyright note

No part of these works may be

reproduced in any form without

permission from the publisher, except for the quotation of brief passages in criticism.

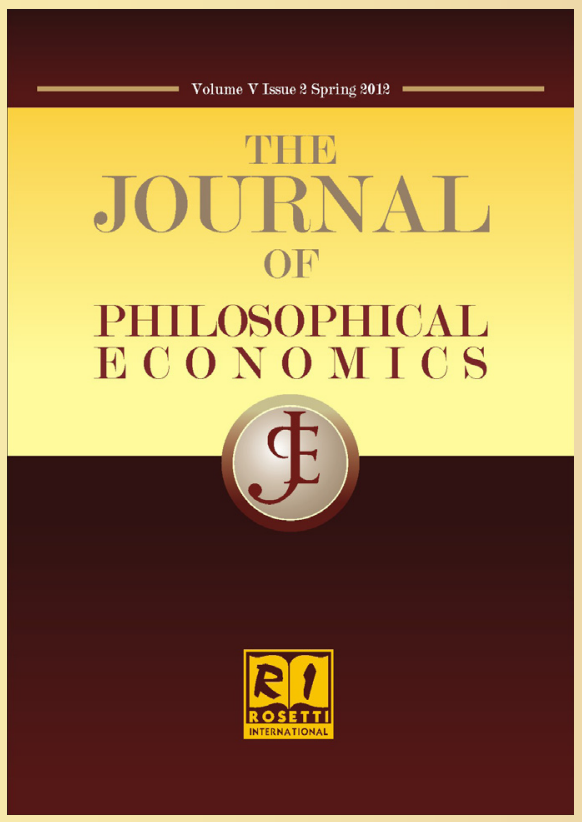

The economist as shaman: revisioning our role for a sustainable, provisioning economy

Molly Scott Cato 
Scott Cato, Molly (2012) 'The economist as shaman: revisioning our role for a sustainable, provisioning economy', The Journal of Philosophical Economics, V:2, 64-83

\title{
The economist as shaman: revisioning our role for a sustainable, provisioning economy
}

\author{
Molly Scott Cato
}

\begin{abstract}
In view of the problems heterodox economists have faced in predicting, explaining and finding solutions to the financial and ecological crises facing humanity, the paper takes a wide-angle view of the question of what the role of an economist might be in a sustainable society. I argue that the role of an economist is one of an intermediary between people and the resources they need for survival, a role that in less rationalist societies might have been performed by a priest or shaman. I propose three central responsibilities for an economist in a sustainable society: supporting a process of re-embedding the economy in the environment; negotiating a respectfuleven reverential - relationship between humans and non-human species; ensuring a means of acquiring resources that minimises the entropic impact of the human community.
\end{abstract}

Keywords: green economy, sustainability, economic methodology

\section{Introduction}

From Gregory Mankiw's suggestion that non-economists may be 'muggles' to Keynes's famous reference to 'animal spirits' in connection with economic activity, and Hazel Henderson's reference to the economics 'priesthood' we may ascertain that there is something worthy of study in the powerful role held by economists in society. In this paper I take a wide perspective on what the role of an economist might be in an anthropological sense, taking a step back and considering what an economist might be for in a general sense, rather than in the sense of a capitalist society in the early 21 st century. 
Scott Cato, Molly (2012) 'The economist as shaman: revisioning our role for a sustainable, provisioning economy', The Journal of Philosophical Economics, V:2, 64-83

Economics is a notoriously unreflexive discipline. Despite the best efforts of the Journal of Economic Methodology and in the midst of the interlinked economic, financial and ecological crises, there is little evidence that the mainstream economies profession has questioned its methods, focus or orientation. Unlike other disciplines, economies is not a contested terrain where different approaches wage more or less seemly academic battles. Rather it is a unified, pro-market, neoclassical majority, whose method is almost exclusively mathematical, against which dissidents launch periodic guerrilla attacks. The failure of the discipline to operate in a reflexive way is best demonstrated by the fact that the accepted wisdom holds that, far from their discipline being in need of rapid and radical revision, what the economic crisis proved was the need for more markets, and more neoclassical economics, rather than a change of focus and more variety of method and theory.

In this paper, rather than launching yet another critical attack on an impervious discipline, I move instead to imagine the role of economist for a sustainable society using the method of the thought experiment. I begin by taking seriously the reverence with which economists are treated in our society. I create an ideal type of a priest figure, the 'shaman', against whom I explore the role and behaviour of an economist. I suggest that the role of an economist is one of an intermediary between people and the resources they need for survival, a role that in less rationalist societies might have been performed by a priest or shaman. I recognise that this is an unusual method, but would argue that to achieve real change requires experimental methods, including experimental methods of thought. The aim of the paper is to explore what this conception of economists as intermediaries implies for our role in an era where overconsumption is threatening our survival as a species and where our lifestyles are threatening the existence of other species, as well as our own.

In the following section I analyse the literature provided by social anthropologists to establish the ideal type of the shaman. I then explore to what extent there already exists a myth of economics and a particularly nonmaterialist role assigned to economists. The following sections explore key aspects of the economist-as-shaman: holding responsibility for the necessary link between provisioning and the local natural environment; and mediating the relationship between humans, non-human animals and other species. The conclusion summarises the role of an economist in a sustainable society as one of: supporting a process of re-embedding the economy in the environment; and 
Scott Cato, Molly (2012) 'The economist as shaman: revisioning our role for a sustainable, provisioning economy', The Journal of Philosophical Economics, V:2, 64-83

negotiating a respectful-even reverential_ relationship between humans and non-human species.

\section{Establishing the ideal type of 'shaman'}

What precisely a shaman is, and how a religious system accorded the label 'shamanism' might be defined, is the source of ongoing debate within the literature of comparative religions. As far back as 1903, when anthropologists were first beginning to take seriously the distinct forms of religious experience and expression that explorers and colonisers were discovering in distant corners of the globe, van Gennep (1903) identified the word 'chamanisme' as one of the most dangerous of the vague words used to describe spiritual belief systems. Western scholars have struggled with this role for which they have found few examples in their own societies: 'a great many subsequent examinations of shamanism as a product of Western theorizing, often framed in terms of a Foucauldian notion of discourse and referring to shamanism as a "construct," "idea," "notion," or "metaphor" (DuBois 2011, p. 111).

In terms of his or her function, the role of the shaman is one of mediation, of inhabiting the liminal space between species or between natural and supernatural worlds. According to one social anthropologist who has studied shamans in various South American cultures: 'The defining characteristic of the shamanic practitioner is, of course, his or her direct access to the normally unseen worlds of spirit and divine power, as well as the ability to channel knowledge garnered from these experiences for the good of a human community' (Glass-Coffin 2010, p. 20\%). Abram shares this view of the shaman as intermediary between human communities and their ecosystem:

'The traditional or tribal shaman, I came to discern, acts as an intermediary between the human community and the larger ecological field, ensuring that there is an appropriate flow of nourishment, not just from the landscape to the human inhabitants, but from the human community back to the local earth. By his constant rituals, trances, ecstasies and "journeys", he ensures that the relation between human society and the larger society of beings is balanced and reciprocal, and that the village never takes more from the living land than it returns to it - not just materially but with prayers, propitiation, and praise.' (Abram1996, p. 7)

The shaman is a challenging and intimidating figure; s/he is not to be dismissed by those exercising only temporal power: "the shaman is a strategic manoeuvre 
Scott Cato, Molly (2012) 'The economist as shaman: revisioning our role for a sustainable, provisioning economy', The Journal of Philosophical Economics, V:2, 64-83

that represents the spirit of dissent. Invoking the shamanic offers a way out for those struggling to free themselves from dominant narratives that come from somewhere else.' (Bussey 2009, p. 30, quoting Nandy). The role of shaman thus validates dissent and thinking that challenges the dominant paradigm. Bussey quotes Nandy as arguing for the ability of the shaman to step outside the existing paradigm, and thus have the potential for creating the new: the 'shaman has one foot in the familiar, one foot outside; one foot in the present, one in the future; or, as some would put it, one foot in the timeless.' (Nandy 200\%, p. 176)

Bussey draws attention to the emancipatory potential of the shaman as a role and as a metaphor. The shaman is permitted to act in ways that are outside social norms: s/he exists in liminal spaces and can ignore the taboos and systems of etiquette that are strictly enforced for other members of society. S/he is also the possessor of arcane knowledge, which is acquired through bizarre rituals not accessible to other members of the tribe. It is too tempting here not to draw a connection with the use of higher mathematies and economistic jargon to exclude mortals from the realms of economic debate. But how else are we to interpret the freedom with which the 'quants' employed by the world's finance houses to create power and value through their CDOs (collaterialised debt obligations) and CDSs (credit-default swaps)? [1] Just as in the world of sorcery, the risks are high because the rewards are great: 'shamans inflict harm, or even kill, in exchange for the powers they impart' (Foutiou 2010).

This review of the anthropological literature on shamans suggests the following characteristics as constitutive of the role of shaman:

- A social authority and the accompanying responsibility to provide challenge to existing power systems;

- A close and revered relationship with the ecosystem;

- Mediation through an intuitive as well as a material understanding of other species;

- The power to offer healing.

\section{Myths of economism or provisioning}

My proposition of the economist as shaman is a provocative one, and can be considered as a thought experiment. To justify that it is an experiment worth conducting requires some evidence that the perception of economists by 
Scott Cato, Molly (2012) 'The economist as shaman: revisioning our role for a sustainable, provisioning economy', The Journal of Philosophical Economics, V:2, 64-83

themselves and by others demonstrates their occupying a peculiar social position and playing a specific cultural role. In a paper musing on the distance between economists' view of the world and that of 'the general public', Mankiw (prominent pro-market economist, author of an undergraduate textbook studied by millions, and adviser to the Bush White House) refers to the latter as 'muggles', implicitly suggesting that he and his fellow economists are the possessors of supernatural powers (Mankiw 2009). Another gesture towards the supernatural powers of the financial function is found in the labelling of a plan to gain agreement about future action by British banks as 'Project Merlin'. [2]

More critically, and from outside what is often referred to as the 'charmed circle' of finance, Henderson long ago engaged in what she called 'Unfrocking the priesthood' of economists, sarcastically referring to the 'snake oil' salesmen she considered presently indulged in the dark arts of modelling and prediction. More recently, and particularly since the collapse of the western capitalist model in $200 \% / 8$, similar critiques have spread in a way it is tempting to see as the overthrowing of a powerful mythological system and its replacement with another- the move from the traditional religious ways to the birdman cult amongst Easter Islanders who found their own survival threatened by the overexploitation and exhaustion of essential resources, perhaps.

I am not alone in considering how the way economics thinks about itself is important in defining its power, nor in interpreting much of the way economists make their case as including elements of myth-making. In a critique of mainstream economic theory from the perspective of ecological economics, Kallis and colleagues characterise 'the myths of economism' which they see as distinct from the economy itself:

'This distinction is roughly parallel to nature as reality of its own and the complex myths traditional people hold about nature and their relation to nature. In traditional societies, myths provide explanations for natural phenomena, facilitate individual and collective decisions, and give meaning and coherence to life. As people act on their myths, their societies and the natural environment are shaped and coevolved around them.'

They argue that 'modern people' similarly act according to belief systems they hold about the world, and that many of these are rooted in the discipline of economics'. We can think of examples such as the economic 'fact' that there is no such thing as a free lunch, or that larger systems are more efficient as a result of 
Scott Cato, Molly (2012) 'The economist as shaman: revisioning our role for a sustainable, provisioning economy', The Journal of Philosophical Economics, V:2, 64-83

'economies of scale'. Kallis and colleagues refer to this complex of myth as 'economism', 'and like traditional beliefs and scientific understanding, economism explains phenomena, facilitates individual and collective decisions, and gives meaning and coherence to our lives.' (Kallis, et al. 2009, pp. 18-19).

While the fact that human societies are guided by myths is a basic understanding in the anthropological literature (for example, the myth of birdman that grew up amongst Easter Islanders as their resources grew scarce, or the cargo cults of the Pacific Islanders encountering greatly more technologically sophisticated cultures), it is, according to Kallis et al., equally true of our intellectually sophisticated, post-Enlightenment society. They contend that the dominant myth of our culture is what they term 'economism', a suggestion that implies both the centrality and the hegemonic nature of the worldview of economics (they do not make this explicit but they are referring here to neoclassical economics).

Norgaard (an ecological economist) gives his own interpretation of economism in another paper that questions the deep dislocation that the traditional economist has given rise to:

'Let me expand on the term 'economism' (belief in the primacy of economies) by distinguishing between actual economic activity and the complex of myths we have developed that sustains our trust in the economy and makes it possible to keep it functioning - possible to keep people, capital, and land working together. This distinction is parallel to the one between nature as a reality of its own and the complex of myths traditional peoples held about nature and their relation to it. Just as traditional myths provide explanations for natural phenomena, facilitate individual and collective decisions, and give meaning and coherence to life, so do modern beliefs about economics and the economy, in similar ways, make meaningful, coordinated life in industrial society possible.' (Norgaard 2011)

To a western, rational mind there is no place for the shaman and his very role is difficult to comprehend, as the conflicting terms witch-doctor, medicine man and wise woman testify. Is this person a healer, a wizard, a seer? Where does his or her power come from that she considers herself the equal of the chief and can strike terror into the hearts of his or her country folk? We can imagine that in societies where survival is considerably less secure than it is in the modern West, people who are considered to have a particular role in controlling the supply of resources are important members of society. 
Scott Cato, Molly (2012) 'The economist as shaman: revisioning our role for a sustainable, provisioning economy', The Journal of Philosophical Economics, V:2, 64-83

Giddens (1991) suggests that a characteristic of modernity is a process of creating institutions and routines that shelter us from the uncomfortable reality of our own human dependence. We 'sequester' this reality, to protect us from these aspects of our lives that would prevent our optimal functioning within society. Barry (2012) views such sequestration as part of a strategy for dealing with the vulnerability which we, as modern humans, feel incapable of acknowledging. The pressure of modern society requires us to inhabit a realm of performed invulnerability, with our risk of sickness, dependence and eventual death being excluded from everyday life.

Perhaps we can suggest that the role of the shaman is to inhabit this realm of what Barry calls 'the occluded', the aspects of our humanity that are taboo within a modern society. One aspect of this occluded realm is the vulnerability of our physical selves; another is our dependence on the natural world. Thus the sequestration of our dependence is closely tied to our disembedding from the natural world that ecofeminists theorise as central to our environmentally destructive behaviour. The role of a mainstream economist is to reinforce this disconnection by frequent and public statement of the strength and power of the global capitalist economy. Perhaps we see here a deeper explanation of the irrational exuberance that always seems particularly pronounced when market conditions reach their most challenging, i.e., just before one of capitalism's periodic bubbles is about to burst (Reinhoff and Rogoff 2009). In his role as shaman the economist is required to maintain the separation between the everyday and the taboo, between the whole and the polluted. His social role is to protect us from the risk of exposing our destructive and occluded vulnerability.

In traditional societies the role of the shaman was a two-faced one. While s/he was responsible for ensuring the provision of resources, s/he also had duties connected with protection and propitiation. Non-rationalist societies that recognise their dependence on the natural world but do not have the scientific understanding that permits an aspiration to control are conscious of the importance of their relationship with the environment and the other species they share it with in a way we are not. An important part of the role of the shaman was to maintain this relationship and to inhabit the liminal space between humans, the environment and other species. An example is found in the ancient Hebrew bible, where Chapter 26 of Leviticus expresses precisely this kind of reverential and awe-filled relationship with the Almighty. In verses 2-5 we find the Lord's promise of abundance, no doubt communicated to the faithful by a 
Scott Cato, Molly (2012) 'The economist as shaman: revisioning our role for a sustainable, provisioning economy', The Journal of Philosophical Economics, V:2, 64-83

shamanic figure, which is balanced by a requirement that Sabbaths shall be kept and the holy sanctuary shall be revered. We can interpret this as a divine guarantee of security of resources, so long as religious strictures are maintained.

\section{Economics, embedding, and resource security}

Given that the acquisition and allocation of resources is central to the discipline of economics, it is surprising that so little attention has been focused on the economist's role as one of mediation between human communities and the natural environment. The explanation is found in the neoclassicals optimistic view about the availability and substitutability of resources, as demonstrated by the following quotation from growth theorist Robert Solow:

'If it is very easy to substitute other factors for natural resources, then there is, in principle 'no problem'. The world can, in effect, get along without natural resources. Exhaustion is an event not a catastrophe... If, on the other hand, output per unit of resources is effectively bounded - cannot exceed some upper limit of productivity which is, in turn, not too far from where we are now - then catastrophe is unavoidable ... Fortunately, what little evidence there is suggests that there is quite a lot of substitutability between exhaustible resources and renewable or reproducible resources.' (Solow quoted in Gowdy and Hubacek 2000). [3]

The reason that there is 'little evidence' is that mainstream economics has not focused much attention on the empirical exploration of resource exhaustion, preferring to assume it away as unproblematic. In a parallel process, the question of the relationship between humans and the natural world has been sidelined by a discipline which uses the phrase 'the exploitation of resources' without any hint of embarrassment.

A notable exception, Karl Polanyi (1944) addresses head on the relational nature of economies, and the issue of the separation of economic systems from the social systems on which they inevitably depend. Polanyi conceived of the economic actor as 'submerged in his social relationships'. To him the 'market economy' was a utopian myth, since it assumed that economic structures could prevail over social structures. Polanyi used the concept of 'embedding' to describe the need for the economy to be enmeshed within a complex system of social rules and cultural norms. His notion of the 'double movement' that posits an in-built pressure to bring the economy back into line with social needs provides a useful counterbalance to the economy as asocial market. 
Scott Cato, Molly (2012) 'The economist as shaman: revisioning our role for a sustainable, provisioning economy', The Journal of Philosophical Economics, V:2, 64-83

Ecofeminist theorists have expanded this notion of embedding to encompass the physical embedding of our economic systems within the natural world. Mellor (2006) characterises the argument as follows: "The core argument of ecofeminist political economy is that the marginalisation of women's work is ecologically dangerous because women's lives as reflected in domestic and caring work represent the embodiedness of humanity, the link of humanity with its natural being. Drawing on the work of feminist economics this is partly an argument about the marginalisation of women's work, much of which takes place outside the market and the monetized economy (Mies 1998; Henderson 1996). However, at a more fundamental level it is an argument about the distinct nature of women's work in being more closely connected to bodily existence, as in the caring work for human bodies, and particularly the vulnerable human bodies of the young, the old and the sick. Mellor (2006) argues that the capitalist market is disembodied and disembedded, carved out of the totality of human existence within the natural world; a sustainable economy, by contrast, would be a provisioning economy, focused on provisioning for the meeting of embodied needs rather than the production of market goods for sale.

According to the bioregionalist critique of modern society, the dislocation of ourselves from our local environment, and the increasing distances between our bodies and the landscapes where the food that nourishes them is produced, has left us physiologically as well as psychologically vulnerable (Sale 1991). The proposal of the bioregional economy implies a reconnection of ourselves with our environment via both time and space (Cato 2011; Cato 2012). This embedding-whether social, as proposed by Polanyi, or environmental, as proposed by the ecofeminists - is not a thin, theoretical business. It implies a wholly different approach to economics as the study of resources, an approach that will be much more strongly embedded in social relations and will bring us closer to the environment-now acknowledged and respected as the source of our resources-rather than separating us from it.

While living with a connected sense of oneself in place is far distant from the experience of a modern, intellectual person, it survives in the lived practice of the remaining cultures who are collected under the anthropological term 'animism'. According to Harvey (2006, ch. xvii), 'Animisms are theories, discourses and practices of relationship, of living well, of realising more fully what it means to be a person, and a human person, in the company of other persons, not all of whom are human but all of whom are worthy of respect.' 
Scott Cato, Molly (2012) 'The economist as shaman: revisioning our role for a sustainable, provisioning economy', The Journal of Philosophical Economics, V:2, 64-83

While this world-view might be hard for many rationalists and academics to stomach, it does hint at a route towards a more embedded and relational approach to our need for finding our resources in the natural world, as do the cultures where animism is, or was until recently, an influential philosophy. An example is the worldview of the aboriginal peoples of Austria, who knew the local environment through a system of spiritually resonant songlines (Chatwin 1988). The initial interpretation of these songlines, or tracks followed by totemic ancestors as they followed their creative journey across the land, is as a way of making geographical sense of place. They enable native peoples to find their way and to find sources of food and water. But they are also systems of meaning, of myths that enable individual identities that build communities, and that facilitate relationships between human communities, animal communities, and the resources they share. Taçon identifies in the songlines a process of using landscape to facilitate connection and relationship, concluding that

'History and archaeology have repeatedly shown that cultures that fail to maintain sustainable connections to large stretches of land do so at their folly. Perhaps if we focused less on computer superhighways and paid more attention to looking after the diversity found along Dreaming Tracks, water courses and resource routes, our own survival would be less threatened.' ('Taçon 2005, p. 2)

Such a deep and spiritually resonant connection between human communities and place is not specific to Australia. Jaye Griffiths (2007) found a similar relationship during her travels in Amazonia, where she discovered that indigenous people know how to "think". The songlines harmonize people with environment. There is no divide. Mankind is a full-singing part, not discordant but as necessary — and as beautiful - as a violin to an orchestra.'

It is superfluous to point out that this sort of understanding enhances human well-being in a range of ways that are impossible to fully comprehend by those of us raised in the dislocated, rationalist culture of the contemporary West. However, perhaps we might find an inkling of it in the way that urban myths are always located in local places. When we hear about the dog that was killed in the microwave or the escaped, psychopathic lunatic, the story always takes place in a locality close to where we hear the story suggesting a lingering need to pin stories to places. This refusal to allow stories to float free of their geographical settings is reminiscent of what Basso found amongst the Western Apache for whom 'wisdom sits in places': 
Scott Cato, Molly (2012) 'The economist as shaman: revisioning our role for a sustainable, provisioning economy', The Journal of Philosophical Economics, V:2, 64-83

'Animals, places, and whole landscapes have meanings, sometimes sobering, sometimes uplifting, but always with a moral dimension. . . every story begins and ends with the phrase "it happened at"... and this anchoring of narrative to places means mention of a place evokes a particular story, which in turn carries a moral standard, and implication for certain types of social relations.' (quoted in Pretty, $200 \%$, p. 160)

There is a risk here of falling into the trap of romanticising or patronising the way of life of people in exotic foreign lands. Yet there are suggestions that we might find traces of a similar embedding in sacred landscapes of our own: Chatwin finds hints of the remnants of European songlines in the Greek myths and the historical myths of these [British] islands. Perhaps we can find similar hints in some of the Celtic festivals and myths that made aspects of our own landscape sacred. Certainly the worship of natural features persisted until the 20th century, in local well-dressing rituals (Ross 196\%, p. 10\%) and the wassailing ceremonies that are still popular as life begins to rewaken following the winter. Deakin (200\%, p. 122), in his eulogy to our native woodlands, suggests that Wessex [4] demonstrates a pattern of Neolithic barrows and stone and timber circles that could represent something similar to songlines: 'If rituals are a way of enacting a story . . . the narrative of the Neolithic monuments in Wessex is about history, origins and people's place in the world. The story may well have been a creation myth, a singing up of the songlines on the land.'

\section{The raw and the cooked}

How have we come to be a species which, while capable of minutely documenting its own imminent extinction, has lost all sense of our connection with the earth which is the source of all well-being and of the other species we share it with?

'How did civilized humankind lose all sense of reciprocity and relationship with the animate natural world, that rapport that so influences (and limits) the activities of most indigenous, tribal peoples? How did civilization break out of, and leave behind, the animistic or participatory mode of experience known to all native, place-based cultures?' (Abram 1996, p. 137)

Famously it was John Locke, the English 'empirical' philosopher- he who is often held responsible through providing an intellectual justification for the ownership of land-who argued that 'beasts abstract not' and therefore are not deserving of respect equivalent to that accorded to humans. Leaving aside the 
Scott Cato, Molly (2012) 'The economist as shaman: revisioning our role for a sustainable, provisioning economy', The Journal of Philosophical Economics, V:2, 64-83

question of whether abstraction can be considered to be a self-evident proof of intellectual or moral progress, what are we to make of Locke's apparently 'empirical' conclusion that animals are not capable of intellectual abstraction? Sagan (197\%) argued that chimpanzees at least demonstrate the ability for abstract reasoning, while several authors make a distinction between the moral status of animals who have been tamed and whose 'domestic' status implies that they owe their lives to human intervention, and wild animals (Callicott 1980; Leopold 1949).

The argument about the intellectual and moral capacities of animals is only a tangential concern of my discussion here, but the relationship we have with animals, and especially how we negotiate this relationship with other species when our provisioning requirements demand their deaths, is of great concern to the economist conceptualised as shaman. Part of the role of the economist as shaman, then, is to overcome the taboo that we inevitably associate with killing other animals who, however irrationally, we experience as our kin. This explains the repeated accounts of indigenous peoples' ceremonies to accompany the death of animals in the hunt:

'Animals had souls, of course, so in all hunting societies some form of ritual apology and forgiveness was necessary before the kill: hence the Navajo praying to the deer before the hunt, the Mbuti cleansing themselves by smoke each morning, the Naskapi pledging to the hunted "You and I have the same mind and spirit." But plants and flowers and trees had spirits, too, every bit as sensate, so almost all early peoples had elaborate ceremonies connected with cutting and harvesting, asking exoneration for the painful removal of some of the Earth's children, and most had stories like the Ojibways', which speak of "the wailing of the trees under the axe", or like the ancient Chinese tales which mention cries of "pain and indignation" from fallen branches.' (Sale 1991, p. 6)

Hunting, the killing of our fellow species to meet our need for food, has its myths and what Snyder refers to as its 'etiquette' in all indigenous societies. The painful process of recognising our dependence on our fellow creatures, and the paradoxical realisation that our sustenance requires their death, demanded rites of propitiation and explanatory or sequestrating myths. It also required training in appropriate behaviour through myth and story-telling. Abram tells a story of the Apache people involving a young hunter who treats his prey without respect, wasting some of its flesh. He suffers permanently as a consequence of his inability to deal appropriately with the relationship between hunter and hunted: 
Scott Cato, Molly (2012) 'The economist as shaman: revisioning our role for a sustainable, provisioning economy', The Journal of Philosophical Economics, V:2, 64-83

'On his way home the boy got dizzy and nearly fell off his horse. Then his nose twitched uncontrollably, like Deer's nose does. Then pain shot up behind his eyes. Then he became scared. He was very sick and nearly died and always had bad luck in hunting'. The moral of the tale is clear, that the sacrifice made by the prey should be respected and not denigrated, and its retelling reminds young hunters that they must kill respectfully and use resources wisely.

A similar technique to bridge the gap between species was the story-telling connected to metamorphosis between humans and animals. These examples of the interchange between species, whether in physical or narrative form, play an important role in mediating our relationship with the environment:

'By invoking a dimension or a time when all entities were in human form, or when humans were in the shape of other animals and plants, these stories affirm human kinship with the multiple forms of the surrounding terrain. They thus indicate the respectful, mutual relations that must be practiced in relation to other animals, plants, and the land itself, in order to ensure one's own health and to preserve the well-being of the human community.' (Abram 1996, p. 121)

We might think that we have developed a long way beyond the system of totemic animals, yet there are hints of this closer relationship with animals in our own names. The Russian name Medvyedev, for example, is derived from the Slavic word for a bear (medved), as is the familiar English forename and surname Arthur (from the Celtic ardd, a bear), while the familiar name Ralph is derived from a Scandinavian root meaning 'counsel of wolf'. These names of people- as well as those of places which abound with animist references- remind us of a time when we knew ourselves to be animals and recognised the horse and bear as our siblings. This connectedness extended as far as enabling an experience of metamorphosis, where the space between different species and between the animate and inanimate worlds could be bridged.

This may be one role for the economist as shaman: to remind us of our commonality with other species and to limit our freedom to exploit them freely and without any recognition of the reverence due to their lives. Shepard portrays this failure to recognise our place in nature as a source of madness exemplified in our restless need to change nature: 'Changing the world becomes an unconscious, desperate substitute for changing the self. We then find animal protectionism, wild-area (as opposed to the rest of the planet) preservation, escapist naturism, and beautification, all of which maintain two worlds, hating 
Scott Cato, Molly (2012) 'The economist as shaman: revisioning our role for a sustainable, provisioning economy', The Journal of Philosophical Economics, V:2, 64-83

compromise and confusing complicated ecological issues with good and evil in people'. (Shepard 1982, p. 17) Rather than feeling a distance from the wild and the natural which we have a duty to 'protect', the route to sanity is rather to recognise the unity and sanctity of all life.

Deep ecologist Arne Naess (1986) carried out research into what we really think about the moral importance of other species and found that some understanding of the relationship between different species has survived the rational revolution in the generalised belief that 'every life-form has its place in nature which we must respect. Midgley (1996, p. 126) interprets Naess's findings as suggesting that:

'people are not orthodox individualists. . . they feel that they live within a vast whole- nature- which is in some sense the source of all value, and whose workings are quite generally entitled to respect.. . From this angle, the burden of proof is not on someone who wants to preserve mahogany trees from extinction. It is on the person who proposes to destroy them.'

This may be one role for the economist as shaman: to remind us of our commonality with other species and to limit our freedom to exploit them freely and without any recognition of the reverence due to their lives. We might be encouraged to learn our place in the family of creatures, and, as we are reminded by Gary Snyder to 'take ourselves as no more and no less than another being in the Big Watershed. We can accept each other all as barefoot equals sleeping on the same ground' (Snyder 1990, p. 26).

This is a hard rather than a soft lesson. An understanding of ecology reduces the risk of romanticising nature, since the food web is a simple illustration of the harsh fact of natural life: we live because others have died. We do not know whether a fox feels guilt as it kills a vole, but for humans who are closely embedded with their natural environment, to live life consciously as part of a family of other creatures, to know that your survival requires the death of your brother or sister, is spiritually challenging. Part of the role of the shaman is to undertake the mediation that makes this daily life-and-death more comfortable. The shaman exists in the liminal space between species, and between the worlds of life and death. S/he therefore has the ability to propitiate and to remove the risk of contamination. 
Scott Cato, Molly (2012) 'The economist as shaman: revisioning our role for a sustainable, provisioning economy', The Journal of Philosophical Economics, V:2, 64-83

\section{Conclusion}

The purpose of this paper has not been to draw a strict academic parallel between the role of a shaman in a traditional society and that of an economist in a modern society. I would not be equipped to undertake such a comparison, especially in view of the wealth of ethnographic and other studies in the field (DuBois 2011). Rather, I have sought to identify the particular role of the shaman - that of mediation - as one that might usefully be applied to an economist in a sustainable society. The shaman is offered as an icon of what an economist might be in a sustainable economy embedded within a healthy ecological environment considered as the source of all wealth, in John Ruskin's famous phrase, 'There is no wealth but life'. I began my argument by suggesting that the ecological crisis is evidence of the breakdown of our relationship with the natural world; in concluding my argument I would suggest the need for economists to take seriously their role as one of mediation between human communities and the resources offered by the environments on which they depend. We might consider in turn the four roles of the shaman derived from the anthropological literature.

The first is the ability to acquire and exercise authority and to challenge existing power systems. At present the overwhelming majority of economists are supportive of the existing economic order. My challenge to the profession is to take seriously its role of mediation and to have the courage to impose boundaries to the acquisition of resources that an ecologically balanced lifestyle requires. A range of ecological crises from climate change to species loss arise from the inability of the human species to live within limits. If my argument for the economist-as-shaman has any merit, then it is clearly within the role of an economist to undertake this important role in an era when politicians shy away from attempting to persuade us of the hard truth that we cannot continue to consume resources as we have in the past. Elsewhere (Cato 2012) I have developed more fully my proposals for a 'bioregional economy' which takes seriously both geographical provisioning boundaries, as well as the energy limits that a serious response to climate change demands.

The second role is one of mediation between humans and their environment. Here the concept of 'embedding' favoured by political economist Karl Polanyi and by contemporary ecofeminists could be used to support the transition to a respectful relationship with the planet and our fellow species. Whatever the 
Scott Cato, Molly (2012) 'The economist as shaman: revisioning our role for a sustainable, provisioning economy', The Journal of Philosophical Economics, V:2, 64-83

appropriate rituals might be in a $21^{\text {st }}$-century society, I would suggest that the role as described by Abram might provide a template: 'The traditional or tribal shaman ensures that the village never takes more from the living land than it returns to it- not just materially but with prayers, propitiation, and praise.' (Abram 1996, p. 7) Recalling Schrodinger's view of life as 'that which attracts a stream of negative entropy to itself' (quoted by Sale 1991 at p. 190), we might develop a view of the economist as an expert in this process of minimising the entropic disturbance caused by human lives, balancing our need for joy and flourishing with our impact on natural systems. Just as there is 'bad medicine' in causing too much disruption to natural relationships and the balance of creatures with the planet, so the modern shaman might negotiate a way to access resources that causes the least entropic disorder. In the terminology of today's economies, he or she would be responsible for managing the trade-off between entropy and well-being.

In the anthropological literature, the shaman is a figure whose wisdom, knowledge and authority are not derived from scientific sources; rather, s/he is required to have intuitive understanding. By contrast, the modern economics profession is dominated by young men skilled in statistical and econometric methods; knowledge of natural systems and human relationships is not required criteria to become an economist. Since the primary role of an economist in a sustainable society would be changing the relationship with the earth, its resources, and other species from one of exploitation to one of mutual respect and relationship, it is clear that different kinds of people having undertaken quite different kinds of training would be required. Far from the computer and the regression model, the training for such an economist would require a direct experience of the wholeness of life, such as that described by Glass-Coffin during her researches into shamanic practices:

'There, beneath a waning gibbous moon on a cool Florida winter night, the scene before me was completely ordinary except that every plant, from the tallest coconut palm to the smallest blade of grass acknowledged and honored my presence... I suddenly realized, viscerally, what I had been writing about for many years: that all Life is co-created as willing humans interact in reverence with the very Ground of Being that sustains us. This co-creation is reflected and nourished by the ways in which we interact with one another, by the ways in which we care for the material world that provides for us, and by the ways in which we relate to a firmament which both inspires and humbles us as we journey.' (Glass-Coffin 2010, p. 210) 
Scott Cato, Molly (2012) 'The economist as shaman: revisioning our role for a sustainable, provisioning economy', The Journal of Philosophical Economics, V:2, 64-83

This brings me to the final characteristic of the shaman: the ability to offer healing. This ability to heal the relationship between human beings, non-human animals and the natural environment would seem to be of vital and urgent importance. The economist-as-shaman would, as previously argued, be required to draw on a range of spiritual and intellectual resources to undertake this work. As ecological and social crises gather momentum, we can only hope that young people with the commitment to undertake this critical role will challenge the existing economic orthodoxy and revitalise the profession.

\section{Acknowledgements}

I am grateful to the editor of the journal and to the two anonymous reviewers, whose helpful comments enabled me to improve the focus of the paper.

\section{Endnotes}

[1] These are just two of the arcane pieces of terminology that have come into popular vocabulary since the Crash. CDOs are ways of repackaging debts with various levels of risk attached in such a way that the resulting saleable 'product' attracts the highest credit rating; CDSs are a form of insurance for risky financial undertakings so that the risk is shared, or so that the interconnections means that the whole finance system will live or die as a single entity.

[2] Project Merlin was an attempt by the top executives of some of the UK's leading banks, under the directorship of former Barclay's CEO John Varley, to take control of the public debate over the future of banks and to offer proposals, especially on the subject of bonuses, to assuage public anger following the 2008 financial crisis and public bailout. For more information see the response from the Treasury: http://www.hm-treasury.gov.uk/press_18_11.htm.

[3] Thanks to Ioana Negru for bringing this quotation to my attention.

[4] Wessex was a kingdom of central-western England during the early Middle Ages, which developed a romantic virtual existence through the novels of $19^{\text {th }}$ century writer Thomas Hardy, most of whose novels were set there. 
Scott Cato, Molly (2012) 'The economist as shaman: revisioning our role for a sustainable, provisioning economy', The Journal of Philosophical Economics, V:2, 64-83

\section{References}

Abram, D. (1996), The Spell of the Sensuous, New York: Vintage.

Barry, J. (2012), The Politics of Actually Existing Unsustainability, Oxford: University Press.

Basso, K. (1996), Wisdom Sits in Places: Landscape and language among the Western Apache, Albuquerque, NM: University of New Mexico Press.

Bussey, M. (2009), 'Six shamanic concepts: charting the between in futures work', Foresight, 11 (2), pp. 29-42

Callicott, J. B. (1980) 'Animal Liberation: A Triangular Affair', Environmental Ethics, 2, pp. 311-338.

Cato, M. S. (2011), 'Home Economics: Towards a Research Agenda for the Bioregional Economy', Environmental Values, 20, pp. 481-501.

Cato, M. S. (2012), The Bioregional Economy: Land, Liberty and the Pursuit of Happiness, London: Earthscan.

Chatwin, B. (1988), The Songlines, London: Penguin.

Deakin, R. (2007), Wildwood: A Jonrney through Trees, London: Hamish Hamilton.

DuBois, T. A. (2011), 'Trends in contemporary research on shamanism', Numen, 58, pp. 100-28.

Foutiou, E. (2010), 'Encounters with Sorcery: An Ethnographer's Account', Anthropology and Humanism, 35 (2), pp. 192-203.

Gennep, Arnold van. (1903), 'De l'emploi du mot 'Chamanisme', Revue de l'histoire des religions, 47, pp. 51-5\%

Giddens, A. (1991), Modernity and Self-identity: Self and Society in the Late Modern Age, Cambridge: Polity Press.

Glass-Coffin, B. (2010), 'Anthropology, Shamanism, and Alternate Ways of Knowing-Being in the World: One Anthropologist's Journey of Discovery and Transformation', Anthropology and Humanism, 35 (2), pp. 204-21\%. 
Scott Cato, Molly (2012) 'The economist as shaman: revisioning our role for a sustainable, provisioning economy', The Journal of Philosophical Economics, V:2, 64-83

Gowdy, J. M. and Hubacek, K. (2000), 'Land, Labour and the Anthropology of Work: Towards Sustainable Livelihoods', International Journal of Agricultural Resources, Governance and Ecology, 1 (1), pp. 17-2\%.

Griffiths, J. (2007), Wild: An Elemental Journey, London: Hamish Hamilton.

Harvey, G. (2006), Animism: Respecting the Living World, Columbia: University Press.

Henderson, H. (1996), Creating Alternative Futures: The End of Economics, West Hartford : Kumerian Press.

Kallis, G., Martinez-Alier, J. and Norgaard, R. B. (2009), 'Paper Assets, Real Debts: An Ecological-Economic Exploration of the Global Economic Crisis', Critical Perspectives on International Business, 5 (1-2), pp. 14-25.

Leopold, A. (1949), A Sand County Almanac, 1966 ed., New York: Ballantine Books.

Mankiw, G. (2009), 'Smart Taxes: An Open Invitation to Join the Pigou Club', Eastern Economic Journal, 35, pp. 14 - 23.

Mellor, M. (2006), 'Ecofeminist political economy', International Journal of Green Economics, 1 (1-2), pp. 139 - 150.

Midgley, (1996), Utopias, dolphins and computers : problems of philosophical plumbing, London: Routledge.

Mies, Maria (1998), Patriarchy and Accumulation on a World Scale, London: Zed Press.

Naess, A. (1986/1989), Ecology, Community and Lifestyle, Cambridge : Cambridge University Press.

Nandy, A. (200\%), Time Treks: The Uncertain Future of Old and New Despotisms, Ranikhet: Permanent Black.

Norgaard, R. (2011), 'Economism and the Night Sky', New Economics Institute blog, http:/www.ecoeco.org/content/2011/01/economism-and-the-night-sky/, 30 January 
Scott Cato, Molly (2012) 'The economist as shaman: revisioning our role for a sustainable, provisioning economy', The Journal of Philosophical Economics, V:2, 64-83

Polanyi, K. (1944), The Great Transformation: The Political and Economic Origins of Our Time, New York: Beacon.

Pretty, J. (200\%), The Earth Only Endures: On reconnecting with nature and our place in it, London: Earthscan.

Reinhoff, C. M. and Rogoff, K. (2009), This Time is Different: Eight Centuries of Financial Folly, Princeton, NJ: University Press.

Ross, A. (196\%), Pagan Celtic Britain, London: RKP.

Sagan, Carl (1978), The Dragons of Eden: Speculation on the Evolution of Human Intelligence, New York: Random House.

Sale, K. (1991), Dwellers in the Land: The Bioregional Vision, rev. ed. (2000), Athens, Ga.: University of Georgia Press.

Shepard, P. (1982), Nature and Madness, Athens: University of Georgia Press.

Snyder, G. (1990), The Practice of the Wild, Berkeley, Calif.: Counterpoint.

Taçon, P. (2005), 'Chains of connection', Griffith Review, ed. 9, http:/

www.griffithreview.com/images/stories/edition_articles/ed9_pdfs/taoned9.pdf

Molly Scott Cato is Professor of Strategy and Sustainability

(University of Roehampton, UK) (molly@gaianeconomics.org) 